2. To: (Receiving organization)

Distribution

5. Proj./Prog./Dept./0iv.:

WM/Process Engineering

8. Originator Remarks:

N/A

11. Receiver Remarks:

3. From: (originating organization)
Waste Tank Process
Engineering
6. cog. Engr.:
B. J. Webb

3. From: (originating Organization)

Waste Tank Process

B. J. Webb
4. Related EDT No.:
\[ \mathrm{N} / \mathrm{A} \]

9. Equip./Component No.: $N / A$

10. System/Btdg./Facility: Tank Farms

12. Major Assm. Dug. No.: N/A

13. Permit/Permit Application No.: $N / A$

14. Required Response Date: $N / A$

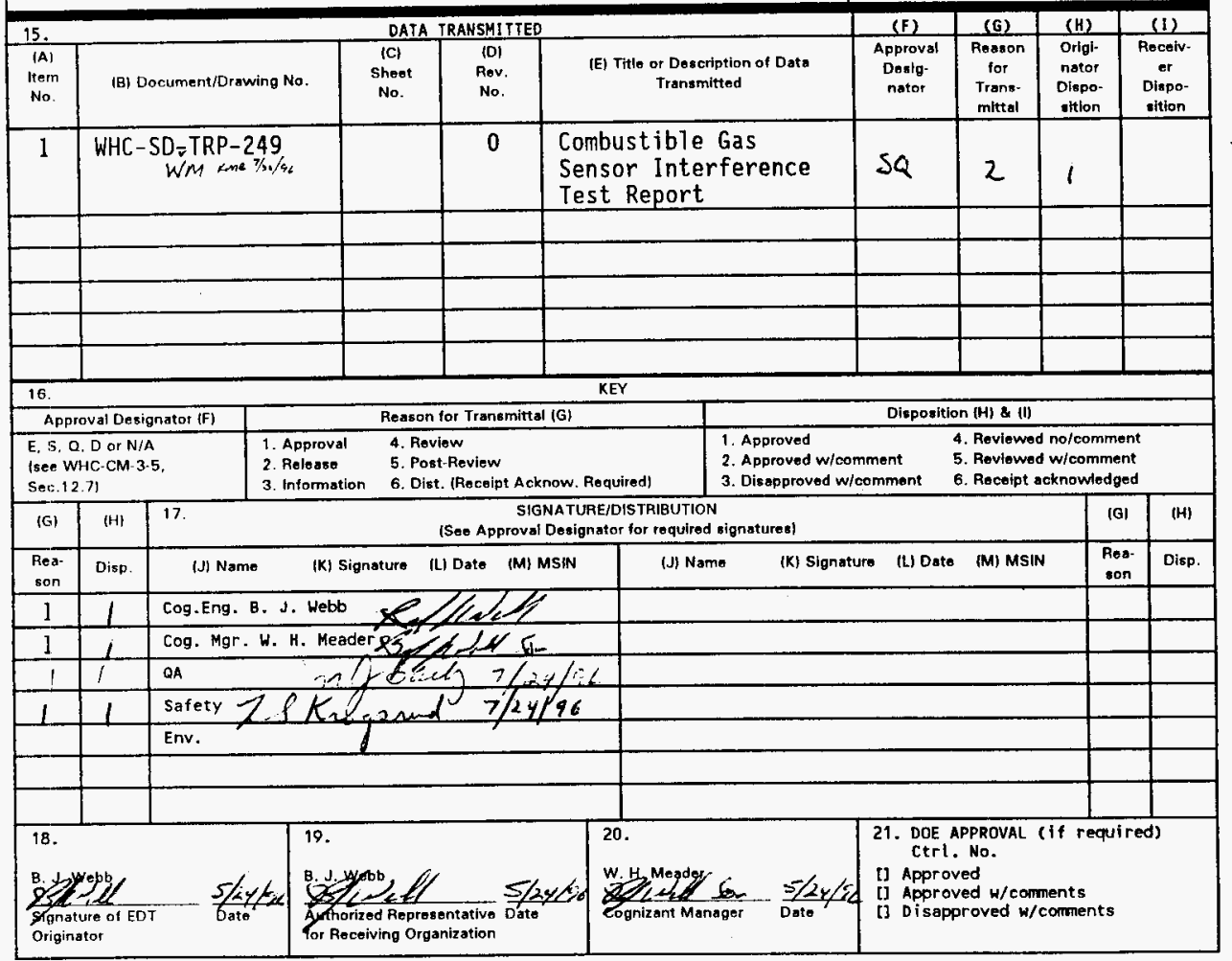




\title{
Combustible Gas Sensor Interference Test Report
}

\author{
B. J. Webb
}

Westinghouse Hanford Company, Richland, WA 99352

U.S. Department of Energy Contract DE-AC06-87RL10930

\author{
EDT/ECN: 615278 \\ Org Code: 74B40 \\ UC: 2030 \\ B\&R Code: EW3120072 \\ Charge Code: $N 1737$ \\ Total Pages: $15 / 6 / 5 / 20 / 2$,
}

Key Words: Flammable Gas; Hydrogen; Ammonia

\section{Abstract:}

Result of Laboratory Interference testing of the Sierra Monitor Corporation Gas Sensor, number model 4101-2, are documnented.

TRADEMARK DISCLAIMER. Reference herein to any specific comercial product, process, or service by irade name, tradenark, manufacturer, or otherwise, does not necessarily constitute or imply its endorsement, recommendation, or favoring by the united states Government or any agency thereof or its contractors or subcontractors.

Printed in the United States of America. To obtain copies of this document, contact: WHC/BCS Document Control Services, P.O. Box 1970, Mailstop H6-08, Richland WA 99352, Phone (509) 372-2420; Fax (509) 376-4989.

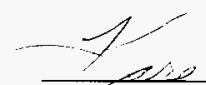

Release Approval

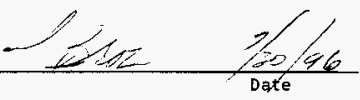

(1)

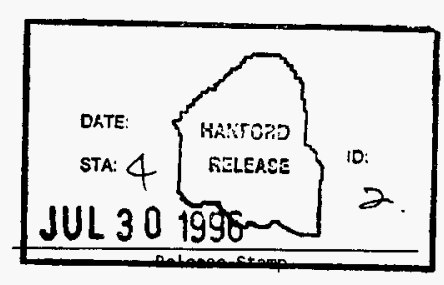

\section{Approved for Public Release}


WHC-SD-WM-TRP-249, Revision 0

COMBUSTIBLE GAS SENSOR INTERFERENCE TEST REPORT

Approval Designator: $S Q$

\author{
Eric K. Straalsund \\ Characterization Monitoring Development \\ and \\ Brent $J$. Webb \\ Waste Tank Stabilization Group
}

May, 1996

Prepared for United States Department of Energy

Westinghouse Hanford Company

P.O. Box 1970

Richland, Washington 99352 


$$
\text { WHC-SD-WM-TRP-249, Revision } 0
$$

\section{COMBUSTIBLE GAS SENSOR}

INTERFERENCE TEST REPORT

TABLE OF CONTENTS

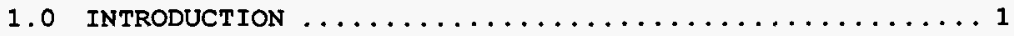

2.0 BACKGROUND $\ldots \ldots \ldots \ldots \ldots \ldots \ldots \ldots \ldots \ldots \ldots \ldots \ldots \ldots \ldots \ldots \ldots \ldots$

3.0 SUMMARY RESULTS AND OBSERVATIONS $\ldots \ldots \ldots \ldots \ldots \ldots$

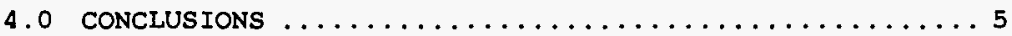

4.1 Detailed Test Description and Data ......... 5

4.2 Pretest Activities .................. 5

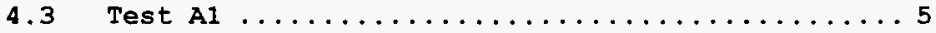

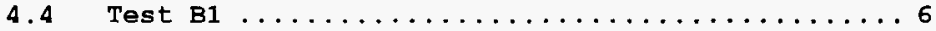

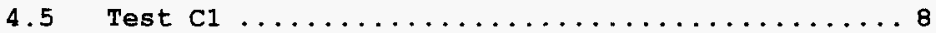

4.6 Tests $I 1$ and $I 2 \ldots \ldots \ldots \ldots \ldots \ldots \ldots$

4.7 Tests $\mathrm{D} 1$ and $\mathrm{D} 2 \ldots \ldots \ldots \ldots \ldots \ldots \ldots \ldots$

4.8 Test $\mathrm{K} 2 \ldots \ldots \ldots \ldots \ldots \ldots \ldots \ldots \ldots \ldots \ldots \ldots$

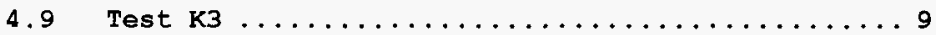

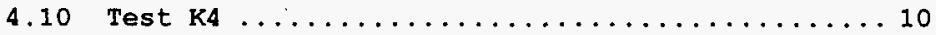

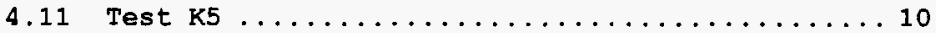

4.12 Response Time Tests Summary ........... 10

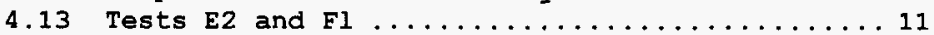

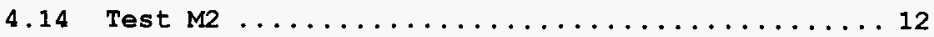

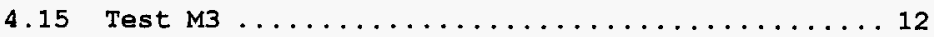

5.0 CONCLUSIONS $\ldots \ldots \ldots \ldots \ldots \ldots \ldots \ldots \ldots \ldots \ldots \ldots \ldots \ldots \ldots$

\section{LIST OF FIGURES}

Figure 1 MC Sensor Response Raw vs. Filtered Signal $\ldots \ldots 6$

Figure 2 Test A1 - SMC Linearity ..............

Figure 3 Test B1 - SMC stability ...............

Figure 4 Test C1 - SMC Warm Up Time..............

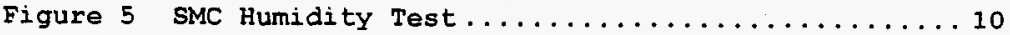

Figure 6 SMC Response Test................. 11

\section{LIST OF TABLES}

Table 1 Test E1 Results .................. 12

Table 2 Test FI Results .................... 12 
WHC-SD-WM-TRP-249, Revision 0

\subsection{INTRODUCTION}

Tests on the SMC combustible gas monitor, Model 4101-2, $\mathrm{s} / \mathrm{N}$ 95-B-4101, were conducted in the 306E gas sensor laboratory beginning July 14, 1995. These tests were conducted per the "Combustible Gas Sensor Interference Test PIan," WHC-SD-WM-TP374. The purpose of the tests was to evaluate sensor range, accuracy, and response time, and the effects of ammonia, nitrous oxide, and humidity on the sensor in the presence of hydrogen gas. 


\subsection{BACKGROUND}

Twenty-five (25) underground storage tanks (USTS) on the Hanford reservation are currently listed on the flammable gas watch list (FGWL). These tanks have been identified as having the potential to contain trapped gases-most notably, trapped quantities of hydrogen, a recognized flammable gas. WHC requires strict work controls and monitoring for all activities conducted in FGWL tanks. Typically, this monitoring for flammable gases on FGWL is accomplished through either the use of a standard hydrogen monitoring system (SHMS) or a hand-held combustible gas analyzer. However, several work activities are planned that require additional process controls such as the ability to automatically shut down or interlock process equipment in the event of a measurable quantity of hydrogen and/or other flammable gas. This test was specifically conducted to assess the applicability of using an SMC combustible gas monitor, Model No. 4101-2, for use in a shutdown interlock system for FGWL tanks. The results of evaluation testing of the sensor are documented herein. 
WHC-SD-WM-TRP-249, Revision 0

\subsection{SUMMARY RESULTS AND OBSERVATIONS}

Testing conducted on the SMC sensor verified that the accuracy and range of the sensor for measuring flammable gas was consistent with the manufacturer's specification of $3 \%$ of full scale or $\pm 10 \%$ of applied concentration, whichever is greater. The lower detection Iimit of the SMC sensor was determined to be about 1000 ppm hydrogen or 2.58 LFL. Sensor response time was measured to be nominally 23 seconds to 608 of final reading when subjected to a step response of $7070 \mathrm{ppm}$ hydrogen in air.

In all cases tested, mixing hydrogen gas with either ammonia or nitrous oxide produced conservative results. No evidence of short-term sensor poisoning from ammonia, nitrous oxide, or water vapor was observed.

Several important observations are worth noting that have direct impact on applications:

1. The sensor tested was not rated for operation in a Class 1 , Division 1, Group B (hydrogen) environment.

2. The output signal of the model tested was noisy and needs to be processed to prevent spurious alarms. This can be rectified by using a Newport voltmeter with signal processing.

3. The response of the sensor was significantly affected by the gas flow rate used in testing. This is common for combustible gas (catalytic bead) sensors as the flow rate affects the heat transfer and thus, affects resultant readings from the sensor. Extreme care should be taken to ensure that the gas flow should be well regulated and constant during normal operations as well as during calibration.

4. The response of the sensor was significantly affected by the vertical and angular orientation of the sensor. This is attributed to the fact that orientation affects heat transfer between the active and passive beads. Because of this, sensor orientation during calibration match that of its intended operation.

5. During subsequent testing of the sensor, calibrations were performed that attempted to "boost" the output and improve low-end resolution by reducing the full scale span of the instrument. In all cases, this "boosted" calibration 
resulted in poor sensor stability and increased drift. It is recommended that the instrument be calibrated using the primary gas of interest (in this case, hydrogen) and calibrated per factory instructions.

6. The SMC sensor is equipped with automatic power-on delay. If power is interrupted to the sensor, output will be set to zero for approximately four minutes. 
WHC-SD-WM-TRP-249, Revision 0

\subsection{CONCLUSIONS}

If proper care is taken to ensure that calibration conditions match operating conditions, the SMC sensor should provide fast, repeatable detection of flammable gas. For applications involving fixed mounting conditions at known gas flow rates, the sensor should provide conservative results provided that the appropriate calibration gas is used. However, because of NEC classification issues and effects of sensor position, the sensor tested should not be considered for the mobile color camera sensor. Several other combustible gas sensors are on the market which would more adequately match this application.

\subsection{Detailed Test Description and Data}

Tests conducted on the SMC sensor were conducted per approved. test procedure. A copy of the completed test procedure and data sheets is provided as the Attachment.

\subsection{Pretest Activities}

The SMC sensor was powered up, calibrated, and hooked up to the LabView data acquisition system. Because the Labview system is a high-speed data acquisition system, we were able to detect an anomaly with the SMC signal that appeared to be a result of the sensor's circuit design. The "noise" was measured by an oscilloscope and determined to be 120 cycles/second and $8.3 \mathrm{kHz}$. A Newport voltmeter with output processing was installed into the system-and the "noise" was effectively filtered, even at the lowest filter setting. Figure 1 shows both the raw and filtered response of the SMC to a series of calibration gas injections.

\subsection{Test A1}

The SMC sensor was calibrated per manufacturer's recommendations and subjected to 10 t step increases from zero to nominal 10,100 ppm hydrogen. The instrument exhibited a nonlinear behavior at the low end and lower detection limit of about $1000 \mathrm{ppm}$. This test was repeated with similar results as Test A2. This experiment was also repeated after recalibrating the sensor using more "gain." Data from this experiment is shown as Figure 2. Examination of Figure 2 shows that with the exception of the high span gas (10,100 ppm hydrogen), all data points are slightly under-reported by the sensor. 


\subsection{Test B1}

The SMC sensor was subjected to a prolonged injection lover 2 hours) of 6705 ppm hydrogen gas to determine stability. Results of this test suggest a stable signal with no appreciable drift over this time frame. Data from Test B1 is shown graphically as Figure 3.

Figure 1. SMC Sensor Response Raw vs. Filtered Signal

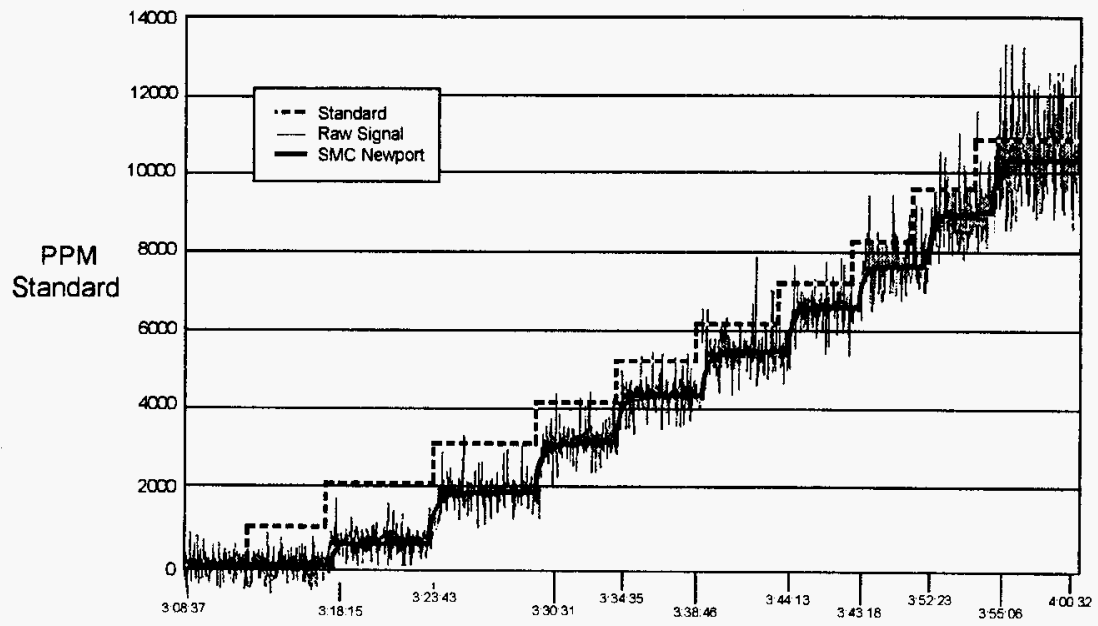

Test Time 
WHC-SD-WM-TRP-249, Revision 0

Figure 2. Test A I - SMC Linearity

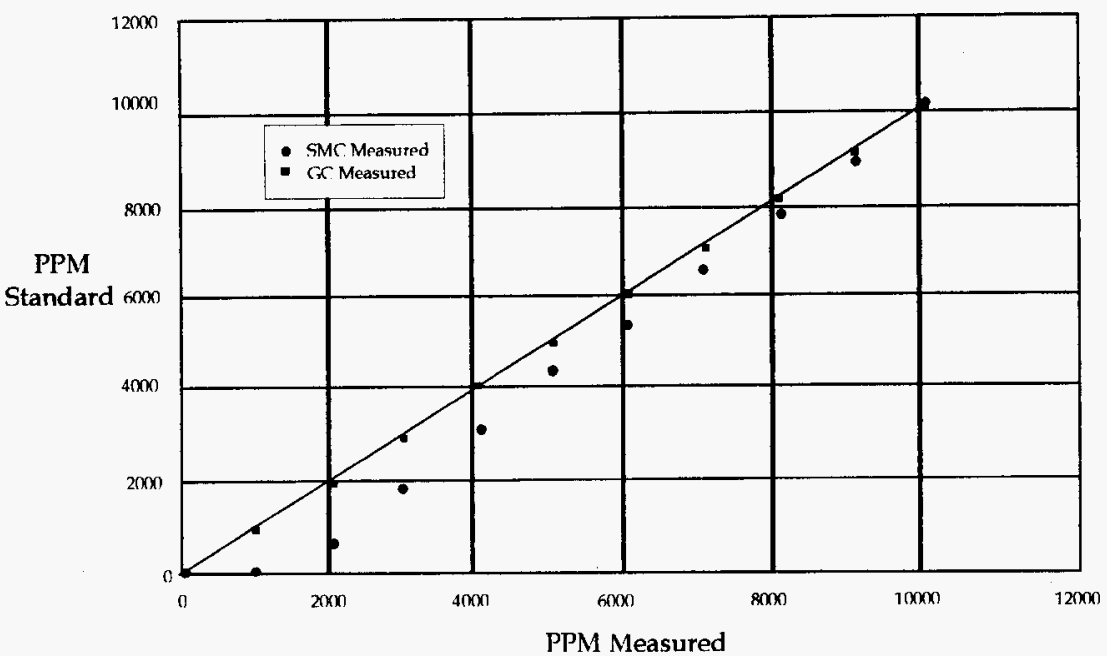

Figure 3. Test BI - SMC Stability / Drift

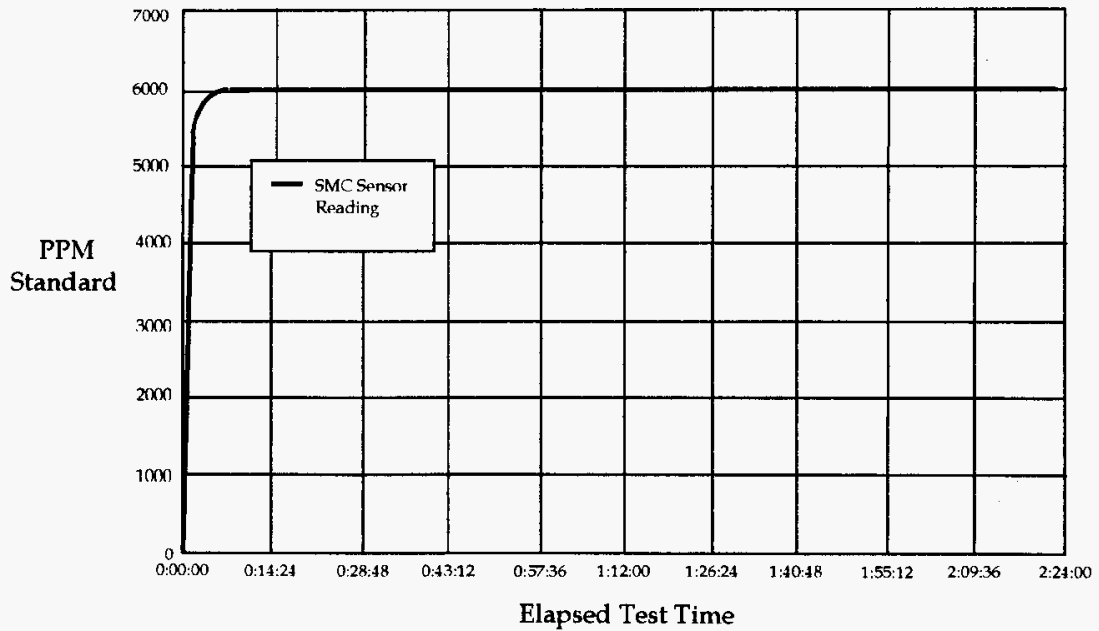




\subsection{Test C1}

The SMC sensor was again tested with 6705 ppm hydrogen, this time after the unit was powered off for over 12 hours. Results from this test verified that the SMC WILL NOT measure hydrogen for 4 minutes following power-down conditions. Response after the four minutes was essentially instantaneous. Figure 4 shows a plot of data from Test C1.

\subsection{Tests II and I2}

These tests, not described in the original test procedure, were conducted to assess the effects of humidity on the SMC response. The tests involved passing the $6705 \mathrm{ppm}$ hydrogen through a bubbler prior to the sensor. The first test indicated a reduced response; however, this was determined to be a result of the time required to purge the relatively large bubbler volume. The test was repeated as Test I2, this time allowing the bubbler to purge prior to hooking up gas to the SMC. Results from this test showed no appreciable decrease in sensitivity or response time as a result of the humidity. Data from Test I2 is shown graphically as Figure 5 .

\subsection{Tests D1 and D2}

Tests D1 and D2 were performed to determine the response time of the SMC sensor. Test D1 applied a step response of 4040 ppm hydrogen, and Test D2 applied a step response of $7070 \mathrm{ppm}$ hydrogen to the SMC sensor. Both tests showed similar results with the SMC sensor approaching $90 \%$ of final reading in about 50 seconds. Data from both tests indicate a "dead" period of about 14 seconds before the sensor starts to respond. This "dead" period may be a result of sensor performance, diffusion through the sintered metal filter, or purge time for the calibration housing. Additional response time tests were performed as Test Series $K$ to examine the repeatability and effects of special calibrations on response time.

\subsection{Test $\mathrm{K} 2$}

A response time test, with a "step" increase of hydrogen from 0 to $7070 \mathrm{ppm}$ hydrogen, was similar to Test D2. Results similar to Test D2 showed about 3 seconds less of "dead" time in sensor response. I attribute this to a better "live" zero calibration. Again, test data emphasize importance of calibrations. 


\subsection{Test $\mathrm{K} 3$}

A response time test was performed immediately after recalibration. The sensor was subjected to a 0-7070 ppm "step" increase. Response time was consistent with response time from Test K2.

Figure 4. Test CI - SMC Warm Up Time

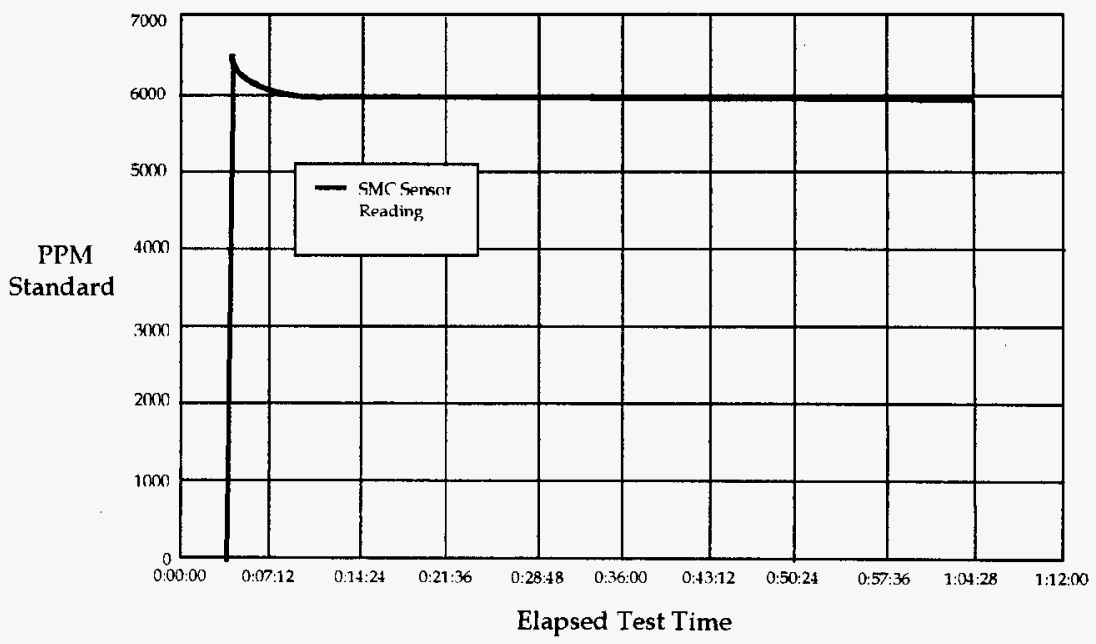


Figure 5. SMC Humidity Test

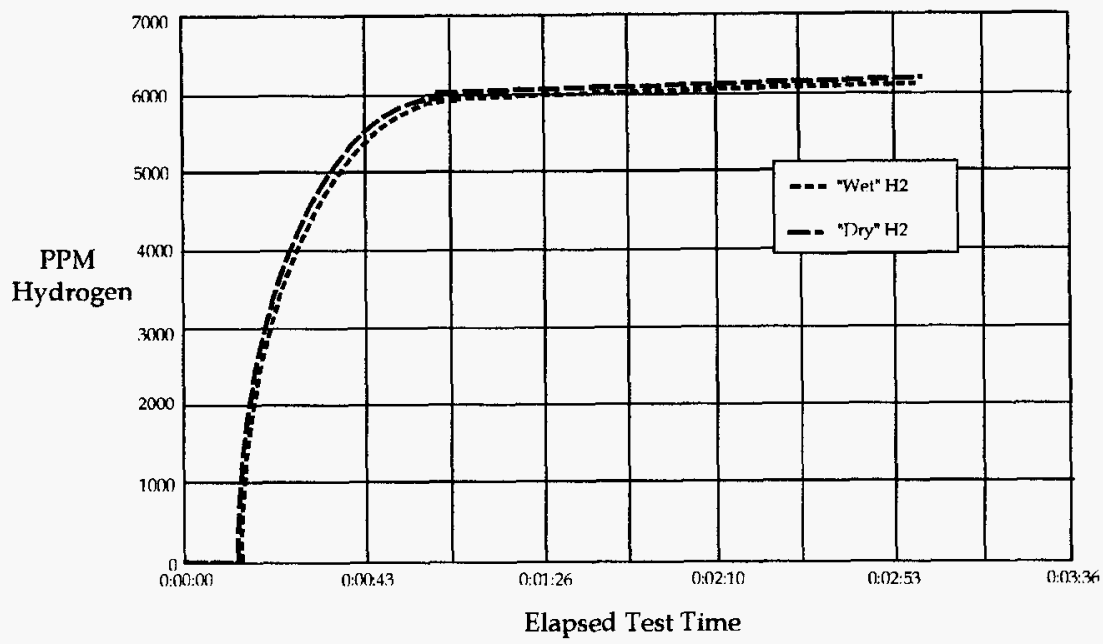

\section{10 Test K4}

The sensor was recalibrated, and Test $\mathrm{k} 3$ was repeated as Test K4. Results were consistent with Test $\mathrm{K} 3$. It was noticed that the output of the sensor was less stable for special "boosted" calibrations in which the full scale span of the sensor was reduced.

\subsection{Test $\mathrm{K5}$}

A sensor response time test was performed. The sensor was subjected to a step increase of $3030-7070 \mathrm{ppm}$. The response time was consistent with previous response time tests.

\subsection{Response Time Tests Summary}

All response time tests showed similar results: the sensor starts to respond in approximately 10 seconds and reaches $60 \%$ response in about 20-25 seconds. This calculated response time calculated from this data is considered to be conservative. This is because it is assumed that the sensor was subjected to a step response in gas concentration while, in reality, the small volume in the calibration head requires time to mix, and a true step 
response cannot be achieved in our current laboratory setup. Test data for all response time tests are shown in Figure 6 .

\subsection{Tests $\mathrm{E} 2$ and $\mathrm{Fl}$}

Tests E2 and F1 were performed to assess the effects of nitrous oxide or ammonia on the SMC. During conduct of the first nitrous oxide test, the lab gas divider malfunctioned and had to be repaired. The test was repeated and no negative interference or "poison" effects from nitrous oxide were observed. However, an interesting phenomenon was noted in that the sensor signal did not stabilize in the presence of high quantities of nitrous oxide. Ammonia testing again showed no negative or poison effects but rather a small (approximately 25\%) increase in signal. Data from these experiments are shown in Table 1 for nitrous-oxide and Table 2 for ammonia.

Figure 6. SMC Response Time Tests

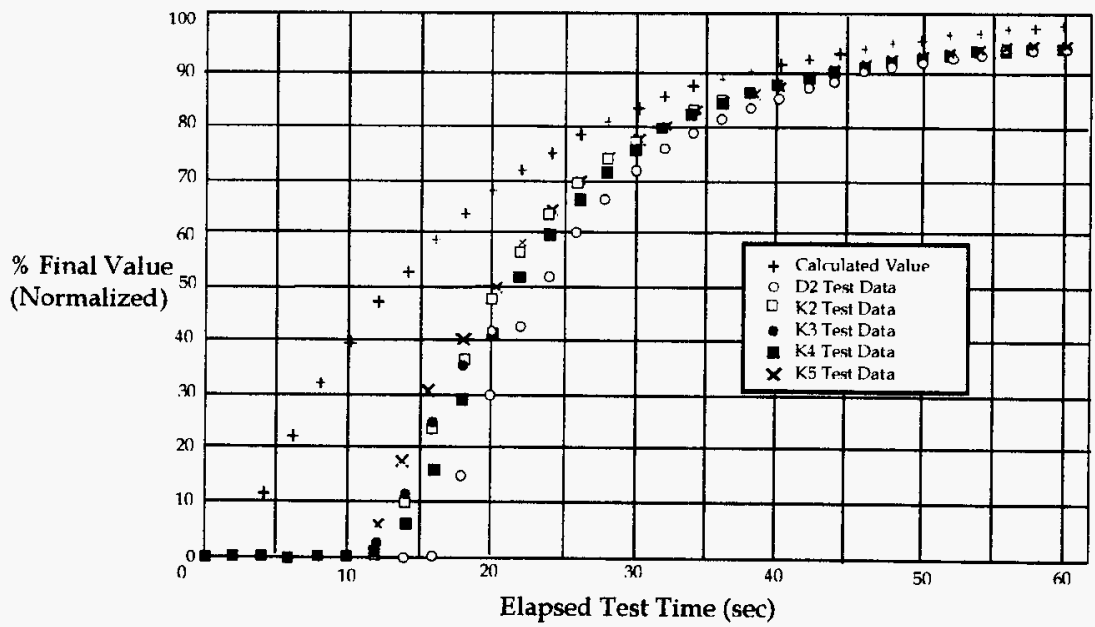


WHC-SD-WM-TRP-249, Revision 0

Table 1. Test E2 Results

\begin{tabular}{rrrrr} 
H2 Standard & N20 & SMC Reading & GC Reading \\
\cline { 1 - 3 } 7450 & 0 & 7085 & 7517 \\
0 & 67700 & & $* 1190$ & 0 \\
7450 & 0 & 7015 & 7549 \\
3725 & 34700 & 3395 & 3815 \\
3725 & 0 & 2609 & 3789
\end{tabular}

*Output climbing after 4 hours.

Table 2. Test Fl Results

\begin{tabular}{crcr} 
H2 Standard & N20 & SMC Reading & GC Reading \\
\cline { 1 - 3 } 10100 & 0 & 9790 & 10179 \\
0 & 5090 & 2110 & 0 \\
10100 & 0 & 10083 & 10218 \\
5050 & 2545 & 6020 & 5163 \\
5050 & 0 & 4690 & 5176
\end{tabular}

\subsection{Test M2}

Approximately $5050 \mathrm{ppm}$ hydrogen at $100 \mathrm{cc} / \mathrm{minute}$ was applied to the sensor, and the sensor was rotated about its horizontal axis. Sensor response was significantly affected by orientation, with over 508 reduction in signal at 180 degree rotation. This implies that sensor position in calibration and operation mode MUST be identical.

\section{15 Test M3}

Approximately $5050 \mathrm{ppm}$ hydrogen was applied to the sensor originally mounted in the horizontal position. Sensor was progressively rotated about the vertical axis in 5 degree increments. Sensor effects were significant but not to the degree noted with rotation about the horizontal axis. Again this test highlights the importance of consistency of position in calibration and operation modes. 


\subsection{CONCLUSIONS}

Tests of the SMC Model 4101-2 combustible gas monitor were conducted in the $306 \mathrm{E}$ gas sensor laboratory. The purpose of the tests was to evaluate sensor range, accuracy, and response time, and the effects of ammonia, nitrous oxide, and humidity on the sensor in the presence of hydrogen gas.

- Tests conducted verified the accuracy and range of the sensor were consistent with the manufacturer's specification of $3 \%$ of full scale or $\pm 10 \%$ of applied concentration, whichever is greater.

- The lower detection limit of the SMC sensor was determined to be about 1000 ppm hydrogen or $2.5 \%$ LFL.

- Tests show the sensor begins to respond in $\sim 10$ seconds after introduce of flammable gases and is capable of reaching 608 of final reading (7070 ppm hydrogen in air) within 20-25 seconds.

- Calibration of the sensor should be performed under the same conditions as sensor operation.

- No evidence of short-term sensor poisoning from ammonia, nitrous oxide, or water vapor was observed.

- Sensor orientation during calibration should match that of its intended operation. 


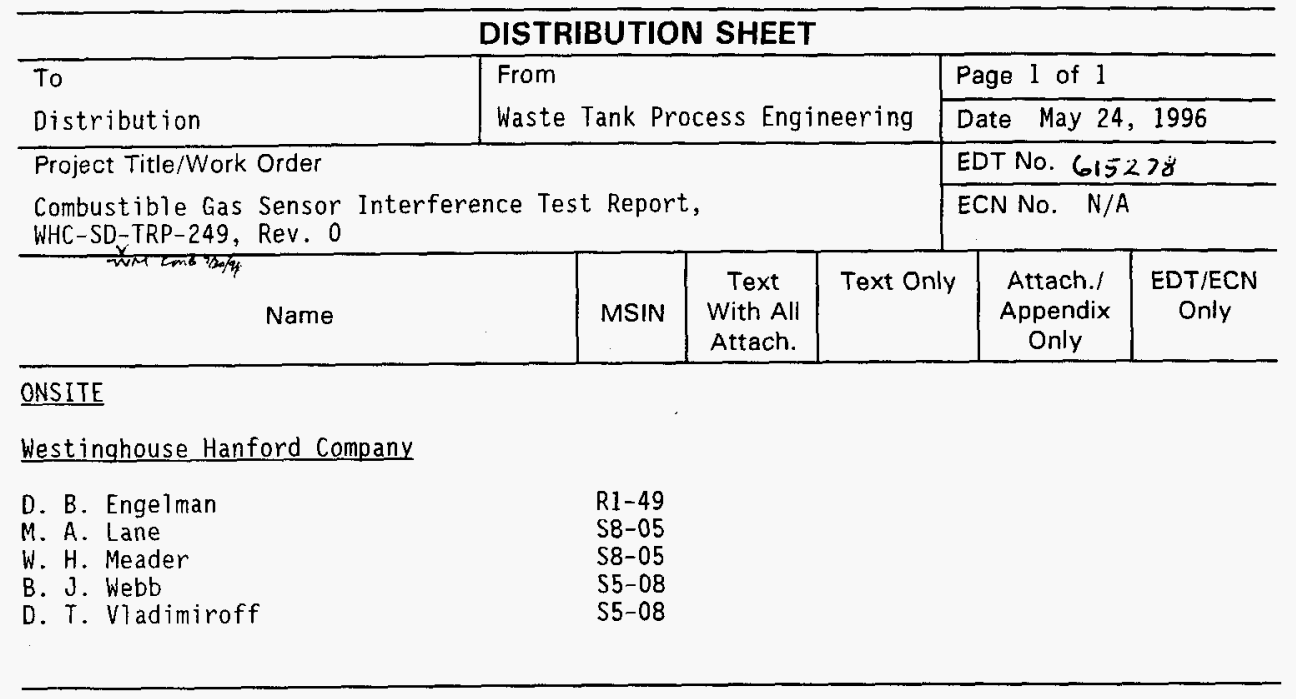

